Original Research Paper

\title{
Preparation of Collagen Casings with High Mechanical Properties using Response Surface Methodology
}

\author{
${ }^{1}$ Zhike Xie, ${ }^{1}$ Ming He, ${ }^{1}$ Yuhan Zhai, ${ }^{1}$ Feifei Xin, ${ }^{1}$ Shuyan Yu, \\ ${ }^{1}$ Shaoxuan Yu, ${ }^{2}$ Huanying Zhao, ${ }^{1}$ Haifang Xiao and ${ }^{1}$ Yuanda Song \\ ${ }^{1}$ Colin Ratledge Center for Microbial Lipids, School of Agricultural Engineering and Food Science, \\ Shandong University of Technology, Zibo, China \\ ${ }^{2}$ Zibo Huanghelong Bioengineering Co. Ltd, Zibo, Shandong, 256400, China
}

\author{
Article history \\ Received: $16-10-2020$ \\ Revised: 12-01-2021 \\ Accepted: 13-01-2021 \\ Corresponding Author: \\ Haifang Xiao \\ Colin Ratledge Center for \\ Microbial Lipids, School of \\ Agricultural Engineering and \\ Food Science, Shandong \\ University of Technology, \\ Zibo, China \\ Email: xiaohaifang@sdut.edu.cn
}

\begin{abstract}
Usages of plastic casing have a number of drawbacks like generation of waste associated with the materials used to package foods and the source of natural casings is limited. So, the interest in the development of biodegradable collagen casing is increasing. For this reason, the present study aimed at developing a new type of collagen casing sprayed with Tea Polyphenols (TP), sodium alginate and sodium pyrophosphate. Box-Behnken Design (BBD) of Response Surface Methodology (RSM) was used to optimize concentrations of TP, sodium alginate and sodium pyrophosphate for the development of collagen casing. The optimization was done on the basis of responses viz. tensile force, tensile strength and elongation at break. The results showed that TP has a significant influence on tensile force and longitudinal tensile strength of collagen casing. Moreover, sodium alginate and sodium pyrophosphate had a significant effect on transverse elongation at break of collagen casing. The optimum level of different parameters resulting in collagen casing with maximum mechanical properties were obtained under conditions of $1.99 \% \mathrm{TP}, 2.90 \%$ sodium alginate and $2.99 \%$ sodium pyrophosphate concentrations. Further verification test of the optimized conditions revealed a sufficient specific accuracy. The new type of collagen casing exhibited good mechanical properties, so these casings can be utilized for packaging in sausage industry.
\end{abstract}

Keywords: Collagen Casings, Mechanical Properties, Response Surface Methodology

\section{Introduction}

Traditional casings are usually the intestines of animals, such as sheep. While these natural casings still have an important place in the market, their nonuniformity, high costs and growing demand have created greater challenges for the sausage industry (Chen et al., 2019). Collagen casings are edible artificial casings made by cleaning, grinding, acid swelling, homogenization, degassing, extrusion, neutralization and drying of the underlying cowhide (Gómez-Estaca et al., 2009). Collagen casings have the advantages of uniformity, hygiene and flexibility and have been recognized as the most promising casings (Harper et al., 2012). It is estimated that about $80 \%$ of sausages require an edible collagen casing, such as hot dogs, Taiwanese sausages (Wang et al., 2015). However, sometimes there will be a series of application problems during the production process. For example, collagen casings can break during filling, deform during fumigation, even fall off the shelves and break or separate from the meat in cooking (Adzaly et al., 2016). It is due to the fact that the collagen molecule loses its triple helix structure to some extent during the extraction process, which affects its mechanical properties (Vergne et al., 2018). In addition, mechanical properties were important during sausage manufacturing because a sausage casing must be tender enough to be pliable during stuffing. Therefore, the mechanical properties (tensile force, tensile strength and elongation at break) of collagen casings need to be improved.

TP is a natural antioxidant of typical flavonoids, which can eliminate reactive oxygen radicals produced by many systems and protect cells from damage (Frei and Higdon, 2003). The main components of TP are Epicatechin (EC), Epicatechin Gallate (EGC), Epicatechin Gallate (ECG) and Epigalate-3-Gallate (EGCG) (Azam et al., 
2004). Recent studies have shown that TP protect against oxidative stress-related diseases, including cancer, cardiovascular and degenerative diseases, as well as other biological activities (Higdon and Frei, 2003). In view of the advantages mentioned above as well as lowcost and safety of TP, the application of TP in the development of edible active packaging film has attracted the attention of many researchers in recent years, such as TP as carrier could improve the antioxidant and antibacterial properties of chitosan film (Zhang and Jiang, 2020). Another research reported that great antioxidant and antimicrobial activity as well as mechanical and water-barrier properties were exhibited in bioactive edible packaging films based on pomelo peel flours (Wu et al., 2019). The incorporation of TP in chitosan films obviously enhanced the antioxidant activity and reduced the water vapor permeability (Wang et al., 2013). Sodium alginate, a kind of bio-adsorbent with excellent adsorption properties, is one of the most studied coating materials because of its advantages such as sustainability, biodegradability, biocompatibility and low toxicity (Gao et al., 2017). At present, the sodium alginate films with essential oils had a considerably high antibacterial effect against foodborne pathogenic bacteria and a strong DPPH radical scavenging ability (Mahcene et al., 2020). The biobased alginate/castor oil edible films obviously improved the mechanical properties and displayed a significant inhibitory effect against $S$. aureus and $B$. subtilis (Gram-positive bacteria) (Aziz et al., 2018). In addition, the alginate film was synthesized from turmeric, TP and blackberry extract also has good physical and mechanical properties (Kalaycığlu et al., 2017; Dou et al., 2018; Kim et al., 2018). Sodium pyrophosphate is the most widely used functional phosphate in meat processing (Shen and Swartz, 2010). To promote gelation, sodium pyrophosphate is often added to meat processing to help extract myofibrillar protein, which then aggregates and gels during cooking (Jongberg et al., 2015).

Response Surface Methodology (RSM) is an empirical modeling method, which is used to assess the impact of multiple independent variables on the response with the goal of optimizing the response, RSM modeling can provide more accurate and complete data with the least number of experiments (Bagheri et al., 2019). Many studies on optimal film formulation have been investigated by using RSM such as the effects of chitosan, glycerin and drying temperature on the response variables of chitosan food film and the effects of pea starch, chitosan and glycerin on the physical, mechanical and barrier properties of pea starch-chitosan food film (Singh et al., 2015; Thakur et al., 2017). Therefore, the objective of this study was to determine the optimization of collagen casing sprayed with different concentration TP, sodium alginate and sodium pyrophosphate using RSM-BBD.

\section{Materials and Methods}

\section{Materials}

The collagen casings (from cowhide and the aperture is $25 \mathrm{~mm}$ ) were offered by Zibo Huanghelong Bioengineering Co., Ltd. (Zibo, China). TP were obtained from Freder Biotechnology Co., Ltd (Suzhou, China). Sodium alginate and sodium pyrophosphate were purchased from Sinopharm Chemical Reagent Co., Ltd. (Beijing, China). All other reagents used in this study were analytical grade. Sterile water was used throughout this study.

\section{Experimental Methods}

\section{Preparation of Collagen Casings}

Collagen casings were cut into $20 \mathrm{~cm}$ lengths and then sprayed with $5 \mathrm{~mL}$ of food additions solution (sodium alginate, sodium pyrophosphate and TP). After treatment for $10 \mathrm{~h}$ at $35^{\circ} \mathrm{C}$, collagen casings were kept in a desiccator at $25^{\circ} \mathrm{C}$ and $50 \%$ Relative Humidity (RH) before further analysis.

\section{Mechanical Properties}

The films were cut into strips $(15 \times 3 \mathrm{~cm}$ in the longitudinal direction, $5 \times 3 \mathrm{~cm}$ in the transverse direction) and stored at $25^{\circ} \mathrm{C}$ and $50 \% \mathrm{RH}$ for $24 \mathrm{~h}$ before measurement. The tensile force, tensile strength and elongation at break of the collagen casings were measured at $25^{\circ} \mathrm{C}$ with a tensile testing machine (XLW; Labthink, China). The tensile tests were performed with a longitudinal gap of $10 \mathrm{~cm}$, a transverse gap of $3 \mathrm{~cm}$ and a crosshead speed of $1 \mathrm{~mm} / \mathrm{s}$.

\section{Response Surface Experimental Design}

In response surface experimental, RSM using BBD was employed to investigate the relationship between three independent variables $\left(\mathrm{X}_{1}\right.$, concentration of sodium alginate; $\mathrm{X}_{2}$, concentration of sodium pyrophosphate; $\mathrm{X}_{3}$, concentration of TP) that was code at three levels $(-1,0,1)$ and six dependent variables $\left(\mathrm{Y}_{1}\right.$, longitudinal tensile force; $\mathrm{Y}_{2}$, transverse tensile force; $\mathrm{Y}_{3}$, longitudinal tensile strength; $\mathrm{Y}_{4}$, transverse tensile strength; $\mathrm{Y}_{5}$, longitudinal elongation at break; $\mathrm{Y}_{6}$, transverse elongation at break) of collagen casings in this study (Table 1). All the ranges of the parameters in RSM were selected based on the results of single factor experiments according to our previous study (Xie et al., 2020). The concentrations of sodium alginate, sodium pyrophosphate and TP varied from 2.5 to $3.5 \%, 2.5$ to $3.5 \%$ and 1.5 to $2.5 \%$, respectively. The uncoded and coded values of the independent variables and the experiment design were depicted in Table 2. The complete design was carried out in a random order and consisted of 17 combinations including 5 replicates at central point and the process flow diagram of collagen casing was shown in Fig. 1. 


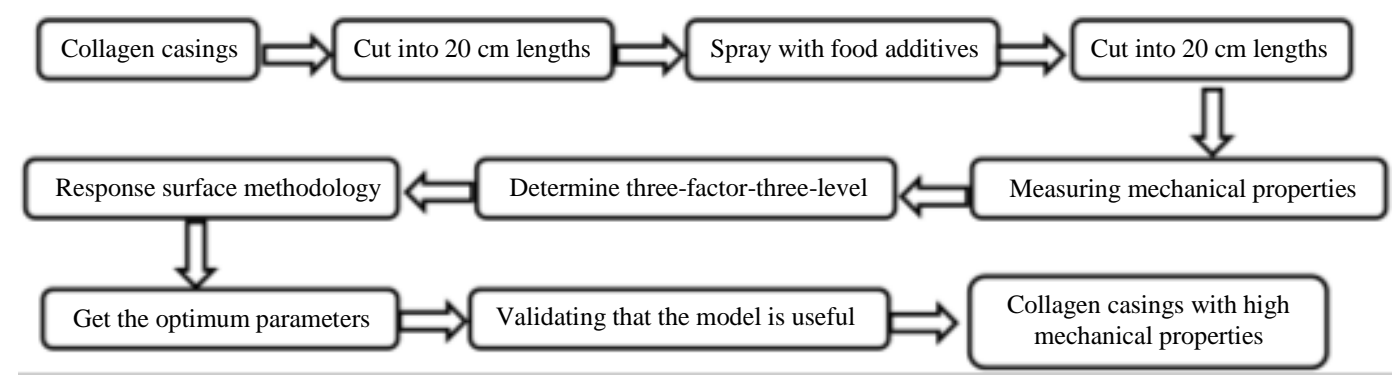

Fig. 1: The process flow diagram of collagen casing with high mechanical properties

Table 1: Independent variables and their code variable levels used for the Box-Behnken design

\begin{tabular}{lllll}
\hline & & & Coded levels \\
No & Independent variables & Symbol & -1 & 0 \\
\hline 1 & Concentration of sodium alginate $(\%)$ & $X_{1}$ & 2.5 & 3.0 \\
2 & Concentration of sodium pyrophosphate $(\%)$ & $\mathrm{X}_{2}$ & 2.5 & 3.0 \\
3 & Concentration of TP $(\%)$ & $\mathrm{X}_{3}$ & 1.5 & 2.0 \\
\hline
\end{tabular}

Table 2: Box-Behnken experimental design and corresponding response values

\begin{tabular}{llllllrlll}
\hline Run order & $\mathrm{X}_{1}(\%)$ & $\mathrm{X}_{2}(\%)$ & $\mathrm{X}_{3}(\%)$ & $\mathrm{Y}_{1}(\mathrm{~N})$ & $\mathrm{Y}_{2}(\mathrm{~N})$ & $\mathrm{Y}_{3}(\mathrm{MPa})$ & $\mathrm{Y}_{4}(\mathrm{MPa})$ & $\mathrm{Y}_{5}(\%)$ & $\mathrm{Y}_{6}(\%)$ \\
\hline 1 & 2.50 & 3.00 & 2.50 & 11.37 & 6.61 & 9.02 & 8.06 & 24.20 & 38.83 \\
2 & 3.50 & 3.50 & 2.00 & 10.49 & 6.10 & 8.66 & 7.92 & 23.40 & 45.67 \\
3 & 3.00 & 3.00 & 2.00 & 12.57 & 7.60 & 10.21 & 9.02 & 25.90 & 48.00 \\
4 & 2.50 & 3.00 & 1.50 & 11.44 & 5.98 & 9.53 & 7.91 & 25.09 & 44.83 \\
5 & 3.00 & 3.00 & 2.00 & 13.01 & 7.23 & 10.05 & 8.40 & 25.89 & 48.00 \\
6 & 2.50 & 2.50 & 2.00 & 11.68 & 6.68 & 9.73 & 8.52 & 25.00 & 42.83 \\
7 & 3.00 & 3.00 & 2.00 & 12.58 & 7.20 & 10.11 & 9.18 & 26.50 & 46.52 \\
8 & 3.50 & 3.00 & 1.50 & 10.02 & 5.87 & 8.34 & 7.82 & 23.90 & 45.68 \\
9 & 3.00 & 3.50 & 1.50 & 10.78 & 5.99 & 8.98 & 7.76 & 24.52 & 43.50 \\
10 & 3.50 & 2.50 & 2.00 & 11.15 & 5.80 & 9.29 & 8.72 & 24.80 & 42.33 \\
11 & 2.50 & 3.50 & 2.00 & 11.68 & 6.75 & 9.73 & 7.95 & 24.62 & 43.89 \\
12 & 3.50 & 3.00 & 2.50 & 10.74 & 5.89 & 8.95 & 7.92 & 23.35 & 39.83 \\
13 & 3.00 & 3.00 & 2.00 & 12.59 & 7.62 & 10.30 & 8.98 & 26.20 & 47.67 \\
14 & 3.00 & 2.50 & 2.50 & 10.89 & 6.02 & 9.23 & 7.68 & 24.95 & 39.33 \\
15 & 3.00 & 3.00 & 2.00 & 12.57 & 7.90 & 9.89 & 8.99 & 25.08 & 46.50 \\
16 & 3.00 & 3.50 & 2.50 & 10.47 & 6.25 & 9.56 & 8.52 & 23.98 & 42.00 \\
17 & 3.00 & 2.50 & 1.50 & 10.56 & 6.23 & 8.80 & 8.43 & 23.35 & 42.30 \\
\hline
\end{tabular}

$\mathrm{X}_{1}=$ Concentration of sodium alginate $(\%), \mathrm{X}_{2}=$ Concentration of sodium pyrophosphate $(\%), \mathrm{X}_{3}=$ Concentration of $\mathrm{TP}(\%), \mathrm{Y}_{1}=$ Longitudinal tensile force $(\mathrm{N}), \mathrm{Y}_{2}=$ Transverse tensile force $(\mathrm{N}), \mathrm{Y}_{3}=$ Longitudinal tensile strength $(\mathrm{MPa}), \mathrm{Y}_{4}=$ Transverse tensile strength $(\mathrm{MPa}), \mathrm{Y}_{5}=$ Longitudinal elongation at break $(\%), \mathrm{Y}_{6}=$ Transverse elongation at break $(\%)$

The relationship between dependent variables (responses) and independent variables was evaluated using a polynomial second-degree model given by the following equation (Hayta and İşçimen, 2017):

$$
Y=\beta_{0}+\sum_{i=1}^{3} \beta_{i} X_{i}+\sum_{i=1}^{3} \beta_{i i} X_{i}^{2}+\sum \sum_{i<j=1}^{3} \beta_{i i} X_{i} X_{j}
$$

where, $Y$ is the dependent variable, $X_{i}$ and $X_{j}$ are the independent variables and $\beta_{0}, \beta_{i}, \beta_{i i}$ and $\beta_{i j}$ are the regression coefficients for intercept, linear, quadratic and interaction terms, respectively.

\section{Statistical Analysis}

The results were expressed as the mean values \pm standard deviations $(n=3)$. One-way Analysis Of
Variance (ANOVA) was implemented by using Origin 8.0 followed by multiple tests in order to determine the significant difference at $\mathrm{p}<0.05$.

\section{Results and Discussion}

\section{The Response Surface Methodology Fitting Model}

Three-factor-three-level experimental design using RSM and BBD was employed to investigate the influence of variables including sodium alginate, sodium pyrophosphate and TP on the mechanical properties of collagen casings. The design matrix and the corresponding responses were summarized in Table 2. Then the data was used to perform multiple linear regressions analysis by a quadratic polynomial model. The results of fitting quadratic models were presented in 
Table 3-5. The result revealed that for the model of six responses (longitudinal and transverse tensile force, tensile strength and elongation at break) p-values were calculated to be $<0.0001,0.0017,0.0025,0.0451,0.0364$ and 0.0022 , respectively. These data were all significant $(\mathrm{p}<0.05)$, indicating that the models constructed in this study had significant regression. Moreover, the result showed that p-values for lack of fit were 0.5561, 0.7148, $0.1183,0.4135,0.3287$ and 0.1111 , respectively. These data above were all more than 0.05 and insignificant, specifying that the mathematical models were satisfactory for prediction of mechanical properties of collagen casings involved in this study.

The coefficient of determination $\left(\mathrm{R}^{2}\right)$ is the square of the coefficient of correlation and illustrates the adequacy of a model. $\mathrm{R}^{2}$ ranges from 0 to 1 . The higher the value of $\mathrm{R}^{2}$, the better the fit of the model (Hayta and İşçimen, 2017). As shown in Table 3-5, the values of $R^{2}$ for six responses (longitudinal and transverse tensile force, tensile strength and elongation at break) were obtained to be $0.9825,0.9395,0.9320,0.8313,0.8418$ and 0.9347 , respectively, implying the close correlation between predicted values and experimental values.

\section{Development of Second Order Polynomial Mathematical Models}

The final regression equations in terms of longitudinal and transverse tensile force, tensile strength and elongation at break were developed respectively as follows:

$$
\begin{aligned}
& Y_{1}=12.66-0.47 X_{1}-0.11 X_{2}+0.084 X_{3}-0.17 X_{1} X_{2}+0.20 X_{1} X_{3}-0.16 X_{2} X_{3}-0.60 X_{1}^{2}-0.82 X_{2}^{2}-1.17 X_{3}^{2} \\
& Y_{2}=7.51-0.30 X_{1}+0.045 X_{2}+0.087 X_{3}+0.057 X_{1} X_{2}-0.15 X_{1} X_{3}+0.12 X_{2} X_{3}-0.61 X_{1}^{2}-0.57 X_{2}^{2}-0.82 X_{3}^{2} \\
& Y_{3}=10.11-0.35 X_{1}-0.015 X_{1}+0.14 X_{3}-0.16 X_{1} X_{2}+0.28 X_{1} X_{3}+0.038 X_{2} X_{3}-0.47 X_{1}^{2}-0.29 X_{2}^{2}-0.68 X_{3}^{2} \\
& Y_{4}=8.91-0.0075 X_{1}-0.15 X_{2}+0.032 X_{3}-0.058 X_{1} X_{2}-0.012 X_{1} X_{3}+0.38 X_{2} X_{3}-0.4 X_{1}^{2}-0.23 X_{2}^{2}-0.58 X_{3}^{2} \\
& Y_{5}=25.91-0.43 X_{1}-0.20 X_{2}-0.048 X_{3}-0.26 X_{1} X_{2}+0.085 X_{1} X_{3}-0.53 X_{2} X_{3}-0.76 X_{1}^{2}-0.70 X_{2}^{2}-1.02 X_{3}^{2} \\
& Y_{6}=47.34+0.39 X_{1}+1.03 X_{2}-2.04 X_{3}+0.57 X_{1} X_{2}+0.038 X_{1} X_{3}+0.37 X_{2} X_{3}-1.57 X_{1}^{2}-2.08 X_{2}^{2}-3.47 X_{3}^{2}
\end{aligned}
$$

\begin{tabular}{|c|c|c|c|c|c|c|}
\hline Indicators & Sources of variation & Sum of squares & df & Mean square & F value & $\mathrm{P}$ value \\
\hline \multirow[t]{15}{*}{$\mathrm{Y}_{1}$} & Model & 13.47 & 9 & 1.500 & 43.72 & $<0.0001^{\mathrm{a}}$ \\
\hline & $\mathrm{X}_{1}$ & 1.78 & 1 & 1.780 & 51.91 & $0.0002^{\mathrm{a}}$ \\
\hline & $\mathrm{X}_{2}$ & 0.092 & 1 & 0.092 & 2.70 & 0.1443 \\
\hline & $\mathrm{X}_{3}$ & 0.056 & 1 & 0.056 & 1.64 & 0.2412 \\
\hline & $\mathrm{X}_{1} \mathrm{X}_{2}$ & 0.11 & 1 & 0.110 & 3.18 & 0.1177 \\
\hline & $\mathrm{X}_{1} \mathrm{X}_{3}$ & 0.16 & 1 & 0.160 & 4.56 & 0.0701 \\
\hline & $\mathrm{X}_{2} \mathrm{X}_{3}$ & 0.10 & 1 & 0.100 & 2.99 & 0.1273 \\
\hline & $\mathrm{X}_{1}^{2}$ & 1.51 & 1 & 1.510 & 44.03 & $0.0003^{\mathrm{a}}$ \\
\hline & $\mathrm{X}_{2}^{2}$ & 2.80 & 1 & 2.800 & 81.86 & $<0.0001^{\mathrm{a}}$ \\
\hline & $\mathrm{X}_{3}^{2}$ & 5.80 & 1 & 5.800 & 169.33 & $<0.0001^{\mathrm{a}}$ \\
\hline & Residual & 0.24 & 7 & 0.034 & & \\
\hline & Lack of fit & 0.090 & 3 & 0.030 & 0.80 & 0.5561 \\
\hline & Pure error & 0.15 & 4 & 0.037 & & \\
\hline & Cor total & 13.71 & 16 & & & \\
\hline & & $\mathrm{R}^{2}=0.9825$ & & & & \\
\hline \multirow[t]{15}{*}{$\mathrm{Y}_{2}$} & Model & 7.31 & 9 & 0.810 & 12.07 & $0.0017^{\mathrm{a}}$ \\
\hline & $\mathrm{X}_{1}$ & 0.70 & 1 & 0.700 & 10.34 & $0.0147^{\mathrm{a}}$ \\
\hline & $\mathrm{X}_{2}$ & 0.016 & 1 & 0.016 & 0.24 & 0.6387 \\
\hline & $\mathrm{X}_{3}$ & 0.061 & 1 & 0.061 & 0.91 & 0.3719 \\
\hline & $\mathrm{X}_{1} \mathrm{X}_{2}$ & 0.013 & 1 & 0.013 & 0.20 & 0.6709 \\
\hline & $\mathrm{X}_{1} \mathrm{X}_{3}$ & 0.093 & 1 & 0.093 & 1.38 & 0.2782 \\
\hline & $\mathrm{X}_{2} \mathrm{X}_{3}$ & 0.055 & 1 & 0.055 & 0.82 & 0.3951 \\
\hline & $\mathrm{X}_{1}^{2}$ & 1.55 & 1 & 1.550 & 22.99 & $0.0020^{\mathrm{a}}$ \\
\hline & $\mathrm{X}_{2}^{2}$ & 1.37 & 1 & 1.370 & 20.42 & $0.0027^{\mathrm{a}}$ \\
\hline & $\mathrm{X}_{3}^{2}$ & 2.81 & 1 & 2.810 & 41.68 & $0.0003^{\mathrm{a}}$ \\
\hline & Residual & 0.47 & 7 & 0.067 & & \\
\hline & Lack of fit & 0.12 & 3 & 0.041 & 0.48 & 0.7148 \\
\hline & Pure error & 0.35 & 4 & 0.087 & & \\
\hline & Cor total & 7.78 & 16 & & & \\
\hline & & $\mathrm{R}^{2}=0.9395$ & & & & \\
\hline
\end{tabular}

Table 3: Analysis of variance for the fit quadratic model of tensile force

${ }^{a}$ Significant difference with $\mathrm{p}<0.05, \mathrm{X}_{1}=$ Concentration of sodium alginate $(\%), \mathrm{X}_{2}=$ Concentration of sodium pyrophosphate $(\%)$, $\mathrm{X}_{3}=$ Concentration of TP $(\%), \mathrm{Y}_{1}=$ Longitudinal tensile force $(\mathrm{N}), \mathrm{Y}_{2}=$ Transverse tensile force $(\mathrm{N}), \mathrm{df}=$ Degree of freedom 
Table 4: Analysis of variance for the fit quadratic model of tensile strength

\begin{tabular}{|c|c|c|c|c|c|c|}
\hline Indicators & Sources of variation & Sum of squares & df & Mean square & F value & $\mathrm{P}$ value \\
\hline \multirow[t]{15}{*}{$\mathrm{Y}_{3}$} & Model & 5.10 & 9 & 0.5700 & 10.660 & $0.0025^{\circ}$ \\
\hline & $\mathrm{X}_{1}$ & 0.96 & 1 & 0.9600 & 18.050 & $0.0038^{\circ}$ \\
\hline & $\mathrm{X}_{2}$ & $1.80 \mathrm{E}-003$ & 1 & $1.80 \mathrm{E}-003$ & 0.034 & 0.8592 \\
\hline & $\mathrm{X}_{3}$ & 0.15 & 1 & 0.1500 & 2.900 & 0.1324 \\
\hline & $\mathrm{X}_{1} \mathrm{X}_{2}$ & 0.099 & 1 & 0.0099 & 1.870 & 0.2140 \\
\hline & $\mathrm{X}_{1} \mathrm{X}_{3}$ & 0.31 & 1 & 0.3100 & 5.900 & $0.0454^{\circ}$ \\
\hline & $\mathrm{X}_{2} \mathrm{X}_{3}$ & $5.62 \mathrm{E}-003$ & 1 & $5.62 \mathrm{E}-003$ & 0.110 & 0.7544 \\
\hline & $\mathrm{X}_{1}{ }^{2}$ & 0.93 & 1 & 0.9300 & 17.580 & $0.0041^{\mathrm{a}}$ \\
\hline & $\mathrm{X}_{2}^{2}$ & 0.35 & 1 & 0.3500 & 6.600 & $0.0371^{\mathrm{a}}$ \\
\hline & $\mathrm{X}_{3}^{2}$ & 1.95 & 1 & 1.9500 & 36.760 & $0.0005^{\circ}$ \\
\hline & Residual & 0.37 & 7 & 0.0530 & & \\
\hline & Lack of fit & 0.27 & 3 & 0.0910 & 3.720 & 0.1183 \\
\hline & Pure error & 0.098 & 4 & 0.0250 & & \\
\hline & Cor total & 5.47 & 16 & & & \\
\hline & & $\mathrm{R}^{2}=0.9320$ & & & & \\
\hline \multirow[t]{15}{*}{$\mathrm{Y}_{4}$} & Model & 3.35 & 9 & 0.3700 & 3.830 & $0.0451^{\mathrm{a}}$ \\
\hline & $\mathrm{X}_{1}$ & $4.50 \mathrm{E}-003$ & 1 & $4.50 \mathrm{E}-003$ & $4.63 \mathrm{E}-003$ & 0.9476 \\
\hline & $\mathrm{X}_{2}$ & 0.18 & 1 & 0.1800 & 1.850 & 0.2156 \\
\hline & $\mathrm{X}_{3}$ & $8.45 \mathrm{E}-003$ & 1 & $8.45 \mathrm{E}-003$ & 0.087 & 0.7766 \\
\hline & $\mathrm{X}_{1} \mathrm{X}_{2}$ & 0.013 & 1 & 0.0130 & 0.140 & 0.7231 \\
\hline & $\mathrm{X}_{1} \mathrm{X}_{3}$ & $6.25 \mathrm{E}-004$ & 1 & $6.25 \mathrm{E}-004$ & $6.43 \mathrm{E}-003$ & 0.9383 \\
\hline & $\mathrm{X}_{2} \mathrm{X}_{3}$ & 0.57 & 1 & 0.5700 & 5.870 & $0.0459^{\mathrm{a}}$ \\
\hline & $\mathrm{X}_{1}^{2}$ & 0.68 & 1 & 0.6800 & 7.050 & $0.0327^{\circ}$ \\
\hline & $\mathrm{X}_{2}^{2}$ & 0.23 & 1 & 0.2300 & 2.360 & 0.1685 \\
\hline & $\mathrm{X}_{3}^{2}$ & 1.43 & 1 & 1.4300 & 14.750 & $0.0064^{\circ}$ \\
\hline & Residual & 0.68 & 7 & 0.0970 & & \\
\hline & Lack of fit & 0.32 & 3 & 0.1100 & 1.210 & 0.4135 \\
\hline & Pure error & 0.36 & 4 & 0.0890 & & \\
\hline & Cor total & 4.03 & 16 & & & \\
\hline & & $\mathrm{R}^{2}=0.8313$ & & & & \\
\hline
\end{tabular}

${ }^{a}$ Significant difference with $\mathrm{p}<0.05, \mathrm{X}_{1}=$ Concentration of sodium alginate $(\%), \mathrm{X}_{2}=$ Concentration of sodium pyrophosphate $(\%), \mathrm{X}_{3}=$ Concentration of TP $(\%), \mathrm{Y}_{3}=$ Longitudinal tensile strength $(\mathrm{MPa}), \mathrm{Y}_{4}=$ Transverse tensile strength $(\mathrm{MPa}), \mathrm{df}=$ Degree of freedom

In the equations above, the positive signs in front of the terms $\left(\mathrm{X}_{1}, \mathrm{X}_{2}\right.$ and $\left.\mathrm{X}_{3}\right)$ symbolized synergistic effect and the negative signs indicated antagonistic effect. Moreover, values in front of the terms higher, impact of the coefficient greater.

\section{Effect of Independent Variables on Tensile Force}

Longitudinal and transverse tensile force of collagen casings ranged from 10.02 to $13.01 \mathrm{~N}$ and 5.8 to $7.9 \mathrm{~N}$ in the RSM experiments (Table 2), respectively. As shown in Table 3, coefficients of $\mathrm{X}_{1}, \mathrm{X}_{1}{ }^{2}, \mathrm{X}_{2}{ }^{2}$ and $\mathrm{X}_{3}{ }^{2}$ were significant based on a $95 \%$ confidence level in affect longitudinal and transverse tensile force of collagen casings, it implied that sodium alginate $\left(\mathrm{X}_{1}\right)$ was the significant variable and had higher impact on longitudinal tensile force and transverse tensile force than sodium pyrophosphate $\left(\mathrm{X}_{2}\right)$ and $\mathrm{TP}\left(\mathrm{X}_{3}\right)$. The interaction effects of the independent variables on the tensile force of collagen casings were presented in Fig. 2 and 3. As illustrated in Fig. 2A and Fig. 3A, the longitudinal and transverse tensile force increased firstly and then decreased as the concentration of sodium alginate increased, which was consistent with our previous research (Xie et al., 2020). We also found that longitudinal tensile force reached the lowest value and transverse tensile force reached highest value when concentration of TP was 1.5 and $1.99 \%$, respectively (Fig. 2C and 3C). However, no significant interaction effects on the tensile force of collagen casings were illustrated between variables (sodium alginate, sodium pyrophosphate and TP) (Table 3, Fig. 2 and 3).

\section{Effect of Independent Variables on Tensile Strength}

In the RSM experiments, longitudinal and transverse tensile strength of collagen casings ranged from 8.34 to 10.3 MPa and 7.68 and 9.18 MPa, respectively (Table 2). As illustrated in Table 4, coefficients of $\mathrm{X}_{1}, \mathrm{X}_{1} \mathrm{X}_{3}, \mathrm{X}_{1}{ }^{2}$, $\mathrm{X}_{2}{ }^{2}$ and $\mathrm{X}_{3}{ }^{2}$ were found to be significant $(\mathrm{p}<0.05)$ in affect longitudinal tensile strength of collagen casings, illustrating that sodium alginate $\left(\mathrm{X}_{1}\right)$ exhibited higher impact on longitudinal tensile strength than sodium pyrophosphate $\left(\mathrm{X}_{2}\right)$ and TP $\left(\mathrm{X}_{3}\right)$ and significant interaction effects on longitudinal tensile strength of collagen casings were demonstrated between sodium alginate and TP (Fig. 4B); to transverse tensile strength of collagen casings, the coefficients of $\mathrm{X}_{2} \mathrm{X}_{3}, \mathrm{X}_{1}{ }^{2}$ and $\mathrm{X}_{3}^{2}$ were significant $(\mathrm{p}<0.05)$ which demonstrated that the effects of three factors on the transverse tensile strength 
were not significant but the interaction between sodium alginate and TP $\left(\mathrm{X}_{2} \mathrm{X}_{3}\right)$ had a significant influence on transverse tensile strength (Fig. 5C). Moreover, the highest longitudinal and transverse tensile strength values were obtained at $2.90 \%$ of sodium alginate concentration and $2.99 \%$ sodium pyrophosphate, respectively. The results from Fig. 4 and 5 also showed that the longitudinal and transverse tensile strength first increased and then decreased with the increase of sodium alginate, sodium pyrophosphate and TP concentrations.

\section{Effect of Independent Variables on Elongation at Break}

The longitudinal and transverse elongation at break of collagen casings varied from 23.35 to $26.5 \%$ and 38.83 to $48 \%$ in the RSM experiments, respectively (Table 2). As shown in Table 5, coefficients of $\mathrm{X}_{1}{ }^{2}, \mathrm{X}_{2}{ }^{2}$ and $\mathrm{X}_{3}^{2}$ were significant based on a $95 \%$ confidence level in affect longitudinal elongation at break of collagen casings, showing that three variables had no significant influence on longitudinal elongation at break and the coefficients of $\mathrm{X}_{2}, \mathrm{X}_{3}, \mathrm{X}_{1}{ }^{2}, \mathrm{X}_{2}{ }^{2}$ and $\mathrm{X}_{3}{ }^{2}$ were significant $(p<0.05)$ in affect transverse elongation at break of collagen casings, implying that sodium pyrophosphate $\left(\mathrm{X}_{2}\right)$ and $\mathrm{TP}\left(\mathrm{X}_{3}\right)$ were the significant variable and had higher impact on transverse elongation at break. These results above as well as results from Fig. 6 and 7 also indicated that there were no significant interaction effects between variables on the elongation at break of collagen casings.

\section{Determination and Validation of Optimized Compositions}

The desirability function was used for simultaneous optimization of the multiple responses. This function enables a combination of independent variables that simultaneously optimizes the requirement for each response in the design. The aim was to maximize six mechanical properties. Therefore, these responses were considered to study the possibility of choosing one formulation which optimizes the mechanical properties of studied collagen casings. The maximum, minimum and average values of these variables experimentally achieved in the Box-Behnken design (Table 2) were applied for calculation of the desirability function.

Table 5: Analysis of variance for the fit quadratic model of elongation at break

\begin{tabular}{|c|c|c|c|c|c|c|}
\hline Indicators & Sources of variation & Sum of squares & $\mathrm{df}$ & Mean square & F value & $\mathrm{P}$ value \\
\hline \multirow[t]{15}{*}{$\mathrm{Y}_{5}$} & Model & 13.11 & 9 & 1.46 & 4.18 & $0.0364^{\mathrm{a}}$ \\
\hline & $\mathrm{X}_{1}$ & 1.50 & 1 & 1.50 & 4.29 & 0.0770 \\
\hline & $\mathrm{X}_{2}$ & 0.31 & 1 & 0.31 & 0.89 & 0.3757 \\
\hline & $\mathrm{X}_{3}$ & 0.018 & 1 & 0.018 & 0.10 & 0.8265 \\
\hline & $\mathrm{X}_{1} \mathrm{X}_{2}$ & 0.26 & 1 & 0.26 & 0.75 & 0.4164 \\
\hline & $\mathrm{X}_{1} \mathrm{X}_{3}$ & 0.029 & 1 & 0.029 & 0.083 & 0.7818 \\
\hline & $\mathrm{X}_{2} \mathrm{X}_{3}$ & 1.14 & 1 & 1.14 & 3.28 & 0.1129 \\
\hline & $\mathrm{X}_{1}^{2}$ & 2.44 & 1 & 2.44 & 7.01 & $0.0330^{\mathrm{a}}$ \\
\hline & $\mathrm{X}_{2}^{2}$ & 2.05 & 1 & 2.05 & 5.87 & $0.0460^{\mathrm{a}}$ \\
\hline & $\mathrm{X}_{3}^{2}$ & 4.35 & 1 & 4.35 & 12.49 & $0.0095^{\mathrm{a}}$ \\
\hline & Residual & 2.44 & 71 & 0.35 & & \\
\hline & Lack of fit & 1.32 & 3 & 0.44 & 1.57 & 0.3287 \\
\hline & Pure error & 1.12 & 4 & 0.28 & & \\
\hline & Cor total & 15.55 & 16 & & & \\
\hline & & $\mathrm{R}^{2}=0.8418$ & & & & \\
\hline \multirow[t]{15}{*}{$\mathrm{Y}_{6}$} & Model & 132.36 & 9 & 14.71 & 11.14 & $0.0022^{\mathrm{a}}$ \\
\hline & $\mathrm{X}_{1}$ & 1.22 & 1 & 1.22 & 0.93 & 0.3676 \\
\hline & $\mathrm{X}_{2}$ & 8.55 & 1 & 8.55 & 6.48 & $0.0384^{\mathrm{a}}$ \\
\hline & $\mathrm{X}_{3}$ & 33.29 & 1 & 33.29 & 25.22 & $0.0015^{\mathrm{a}}$ \\
\hline & $\mathrm{X}_{1} \mathrm{X}_{2}$ & 1.30 & 1 & 1.30 & 0.98 & 0.3542 \\
\hline & $\mathrm{X}_{1} \mathrm{X}_{3}$ & $5.62 \mathrm{E}-003$ & 1 & $5.62 \mathrm{E}-003$ & $4.26 \mathrm{E}-003$ & 0.9498 \\
\hline & $\mathrm{X}_{2} \mathrm{X}_{3}$ & 0.54 & 1 & 0.54 & 0.41 & 0.5427 \\
\hline & $\mathrm{X}_{1}{ }^{2}$ & 10.43 & 1 & 10.43 & 7.90 & $0.0261^{\mathrm{a}}$ \\
\hline & $\mathrm{X}_{2}^{2}$ & 18.29 & 1 & 18.29 & 13.85 & $0.0074^{\mathrm{a}}$ \\
\hline & $\mathrm{X}_{3}{ }^{2}$ & 50.74 & 1 & 50.74 & 38.43 & $0.0004^{\mathrm{a}}$ \\
\hline & Residual & 9.24 & 7 & 1.32 & & \\
\hline & Lack of fit & 6.88 & 3 & 2.29 & 3.89 & 0.1111 \\
\hline & Pure error & 2.36 & 4 & 0.59 & & \\
\hline & Cor total & 141.60 & 16 & & & \\
\hline & & $\mathrm{R}^{2}=0.9347$ & & & & \\
\hline
\end{tabular}

a Significant difference with $\mathrm{p}<0.05, \mathrm{X}_{1}=$ Concentration of sodium alginate $(\%), \mathrm{X}_{2}=$ Concentration of sodium pyrophosphate $(\%), \mathrm{X}_{3}=$ Concentration of TP $(\%), \mathrm{Y}_{5}=$ Longitudinal elongation at break $(\%), \mathrm{Y}_{6}=$ Transverse elongation at break $(\%), \mathrm{df}=$ Degree of freedom 


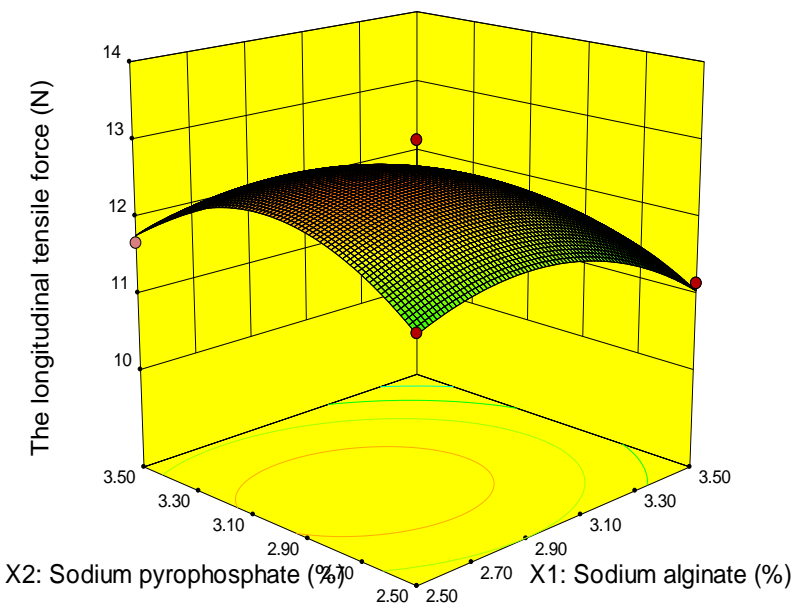

(A)

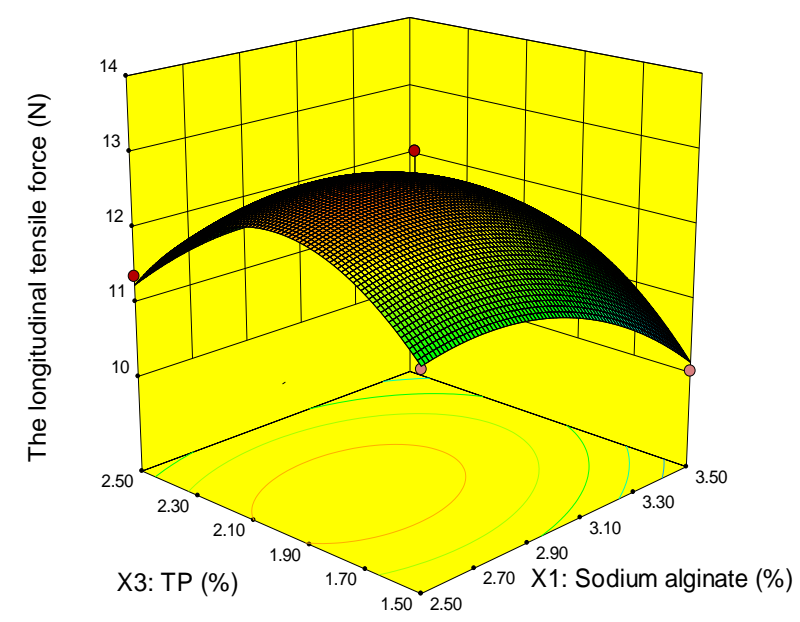

(B)
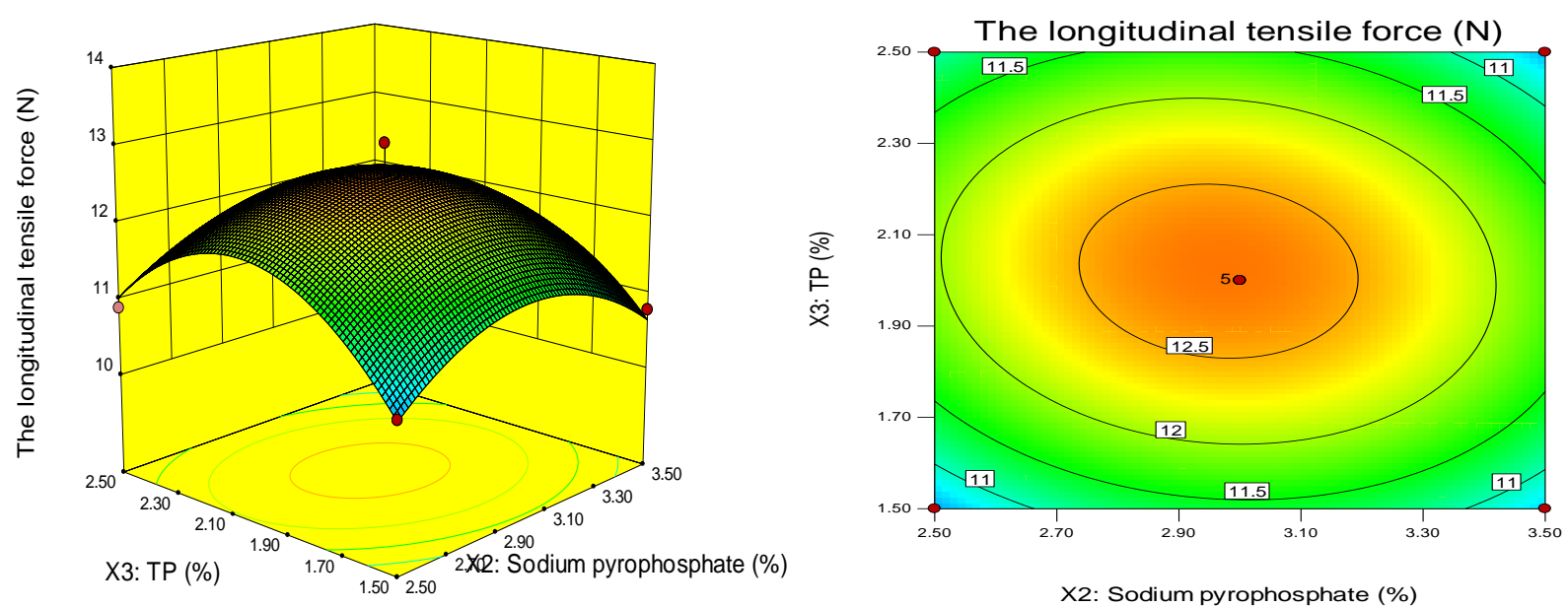

X2: Sodium pyrophosphate (\%)

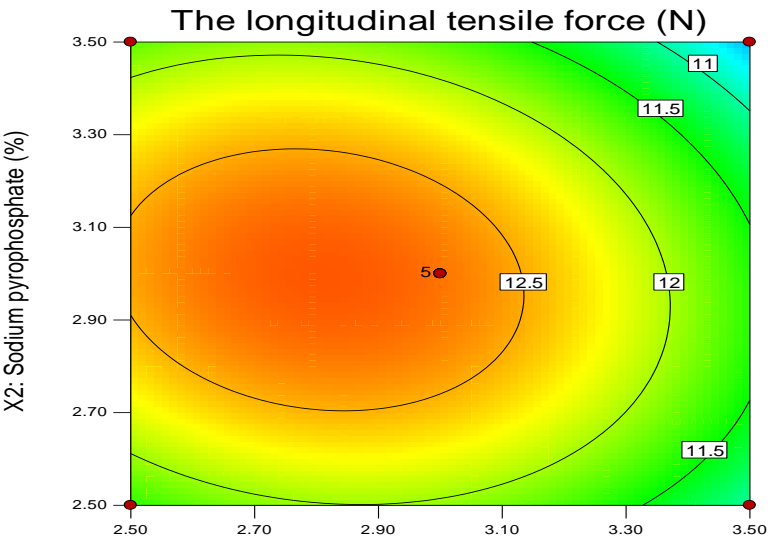

X1: Sodium alginate $(\%)$

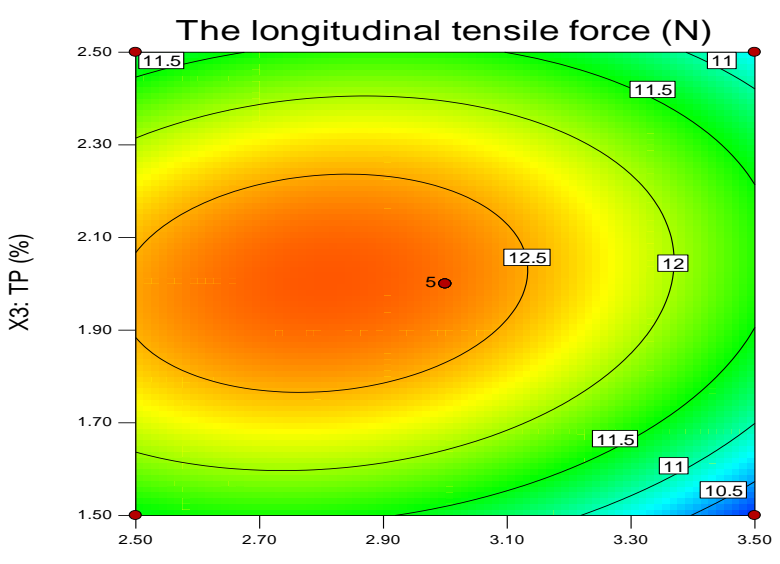

X1: Sodium alginate $(\%)$

(C)

Fig. 2: Response surface plots (3D) and contour plots of longitudinal tensile force as a function of significant interaction between factors. (A) Concentration of sodium alginate and sodium pyrophosphate; (B) Concentration of sodium alginate and TP; (C) Concentration of sodium pyrophosphate and TP 


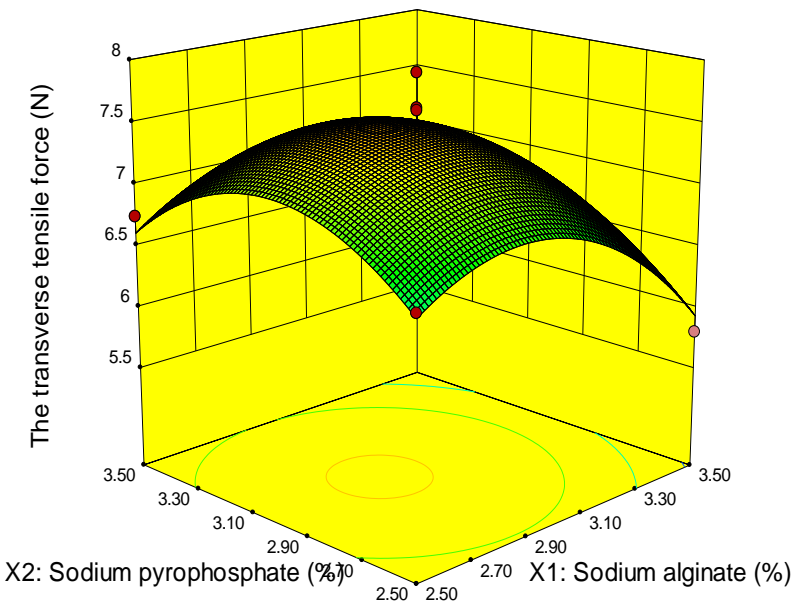

(A)

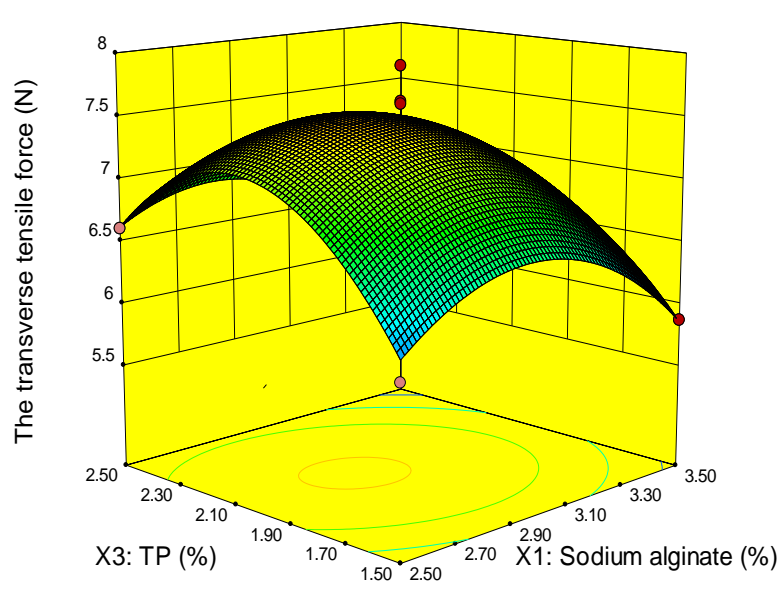

(B)

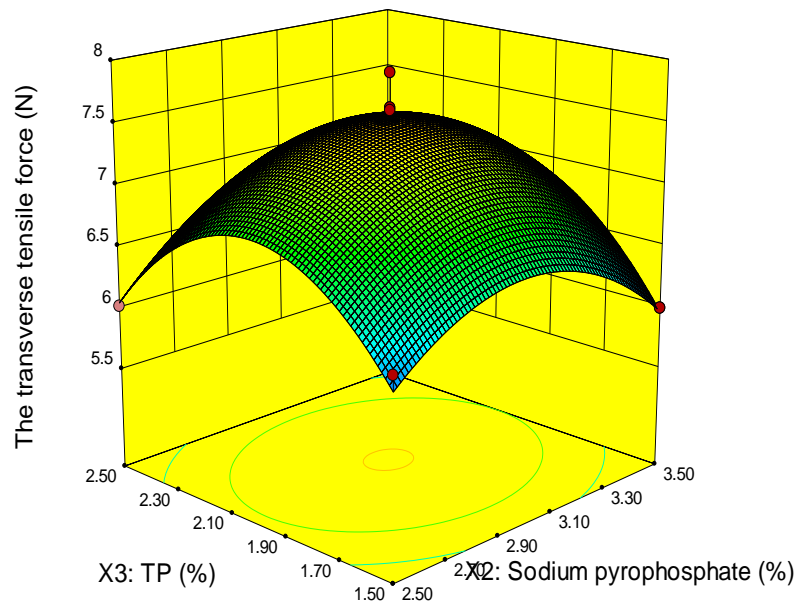

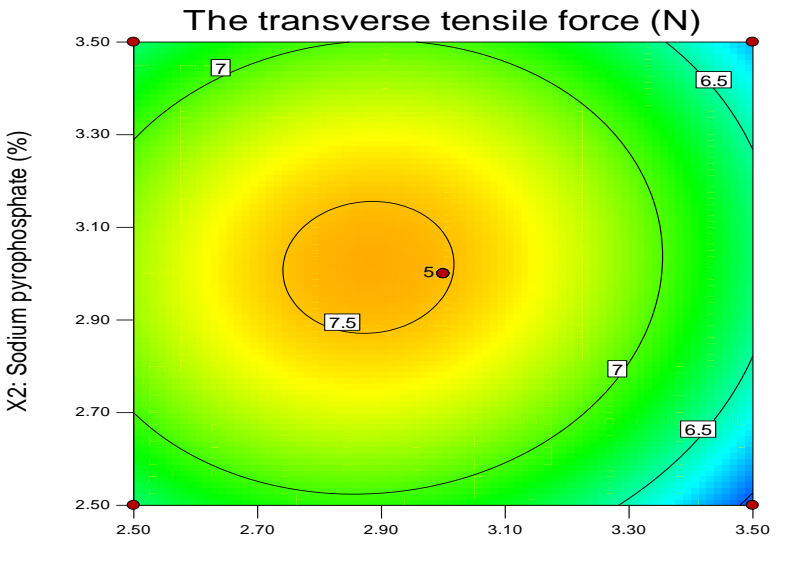

X1: Sodium alginate $(\%)$

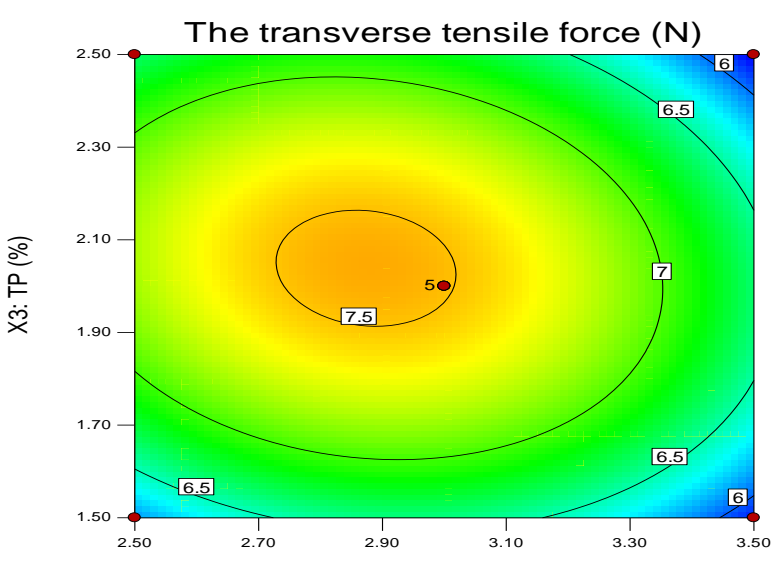

X1: Sodium alginate $(\%)$

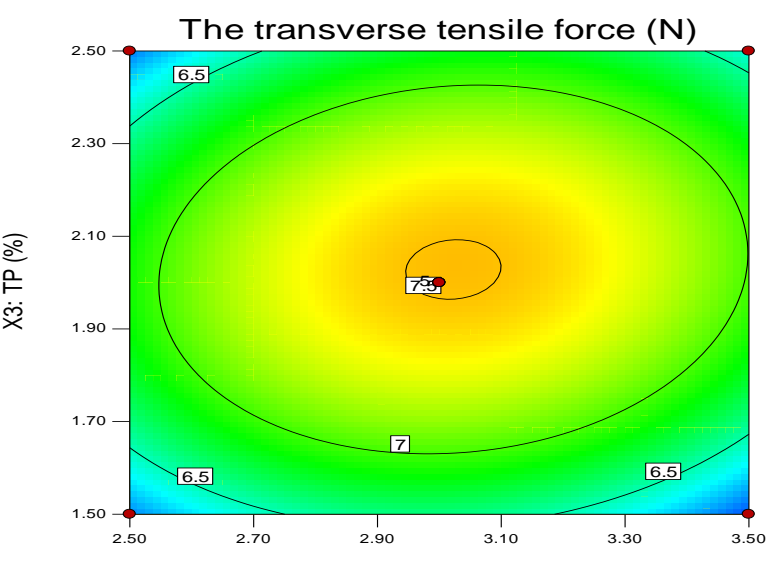

X2: Sodium pyrophosphate (\%)

(C)

Fig. 3: Response surface plots (3D) and contour plots of transverse tensile force as a function of significant interaction between factors. (A) Concentration of sodium alginate and sodium pyrophosphate; (B) Concentration of sodium alginate and TP; (C) Concentration of sodium pyrophosphate and TP 


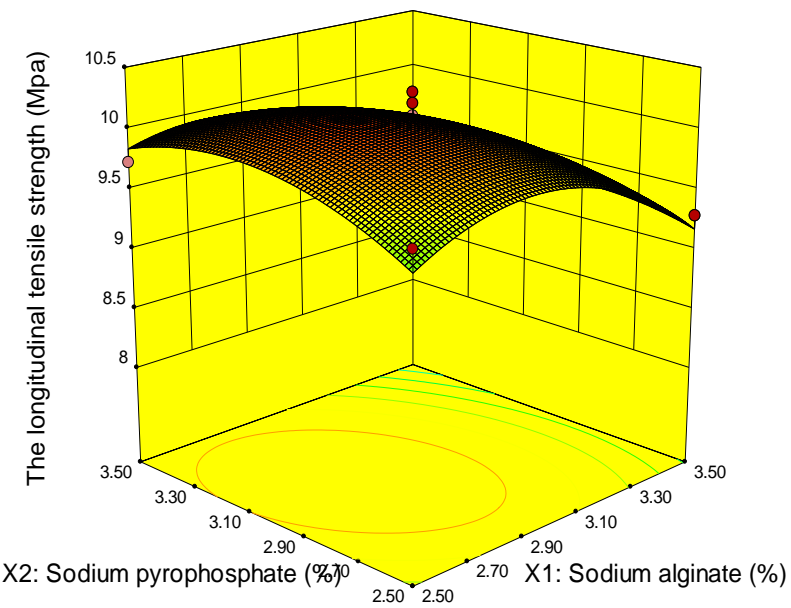

(A)

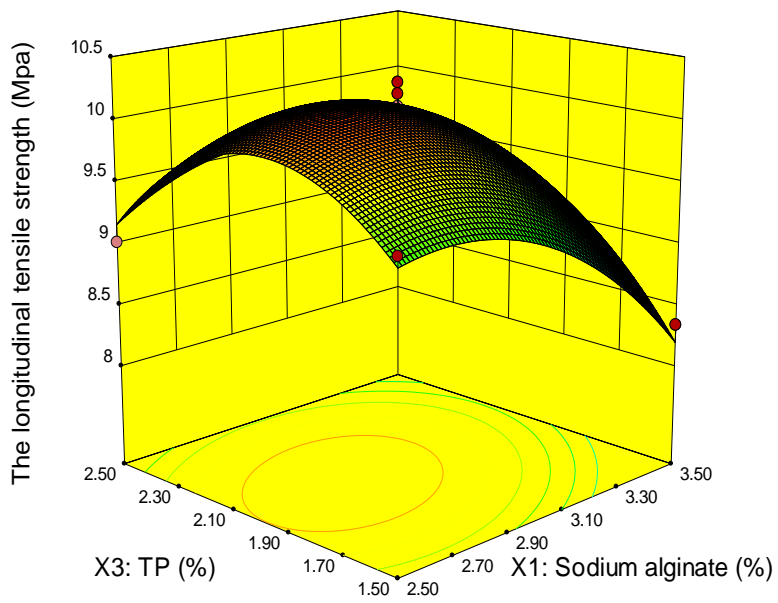

(B)

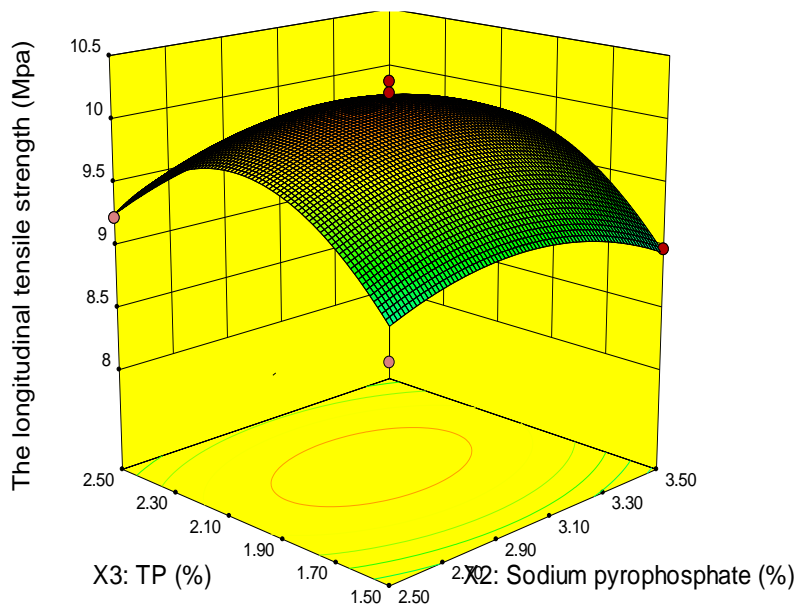

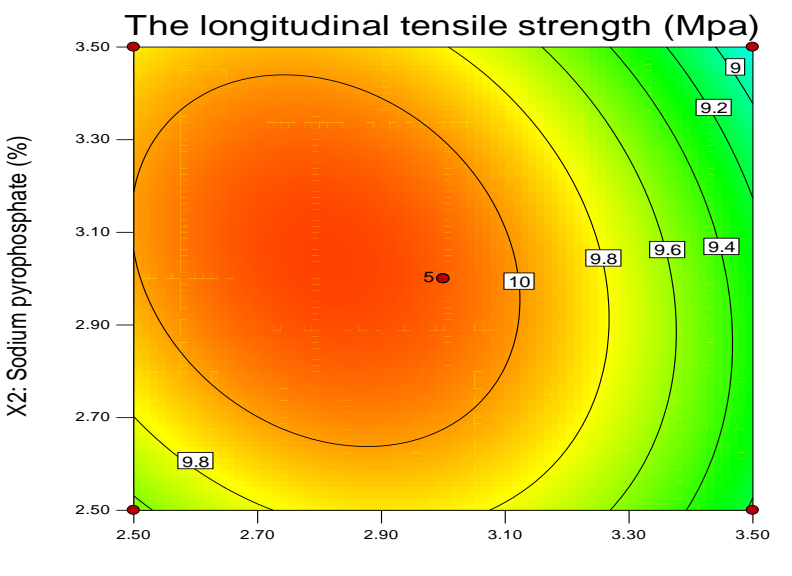

X1: Sodium alginate $(\%)$

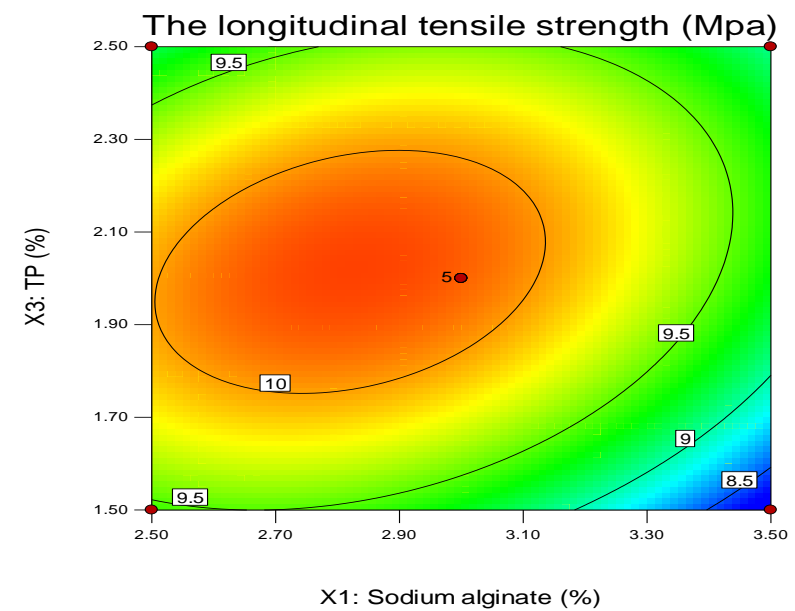

X1: Sodium alginate (\%)

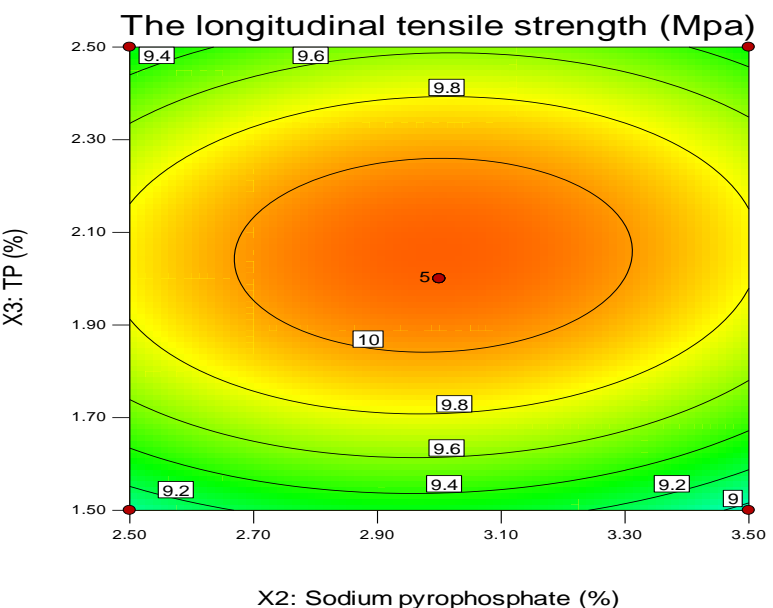

(C)

Fig. 4: Response surface plots (3D) and contour plots of longitudinal tensile strength as a function of significant interaction between factors. (A) Concentration of sodium alginate and sodium pyrophosphate; (B) Concentration of sodium alginate and TP; (C) Concentration of sodium pyrophosphate and TP 


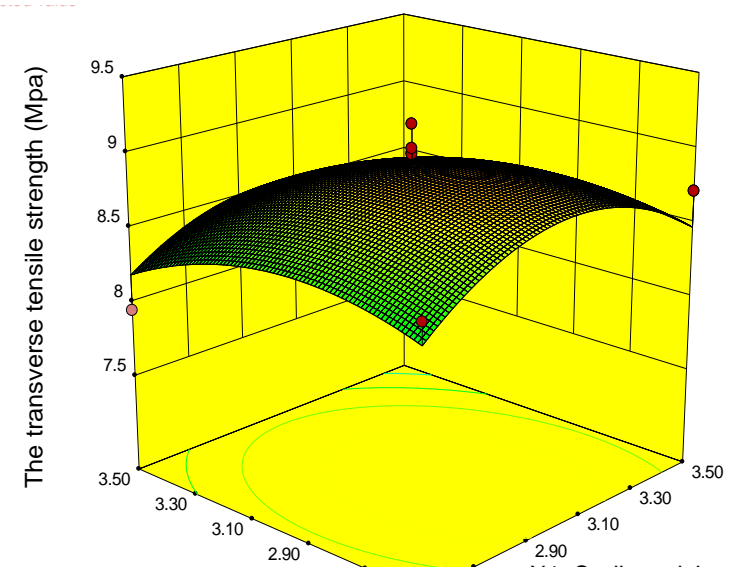

X2: Sodium pyrophosphate $(\% \%)^{\circ} \quad \begin{array}{llll}2.50 & 2.50 & 2.70 & \text { X1: Sodium alginate (\%) }\end{array}$

(A)

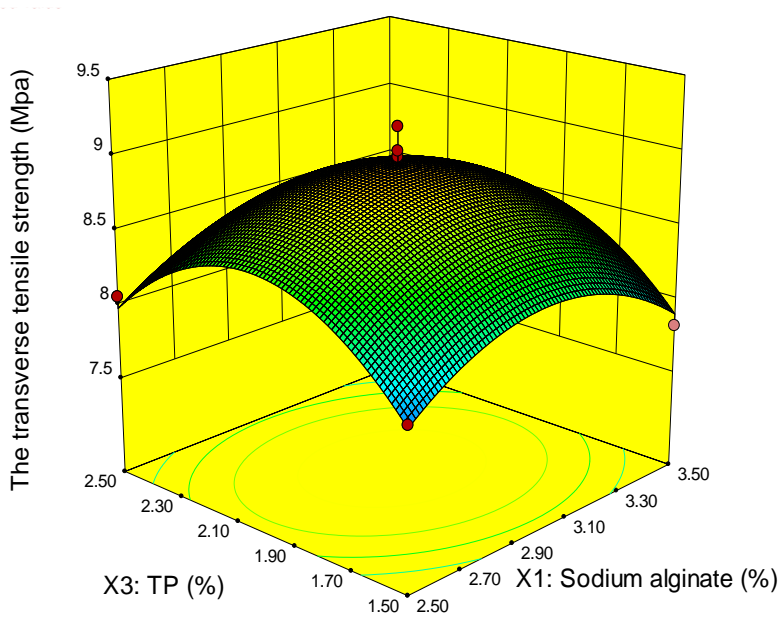

(B)

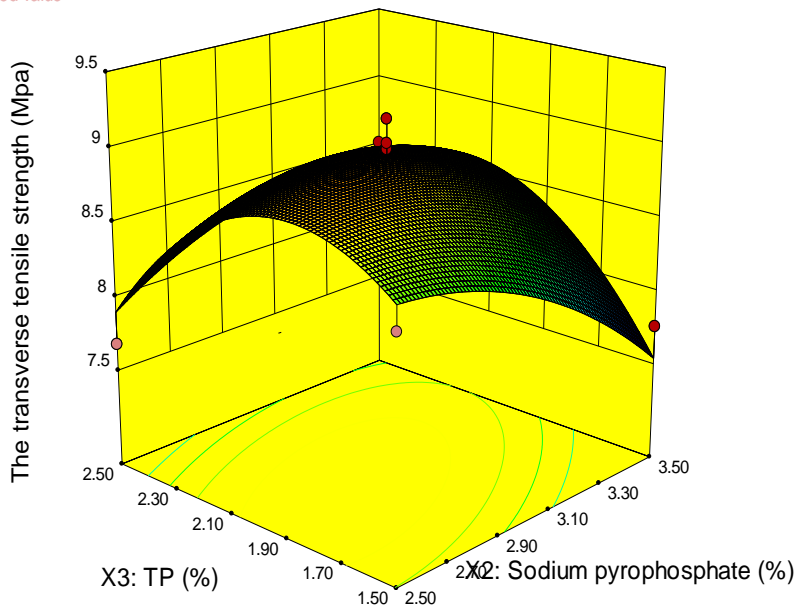

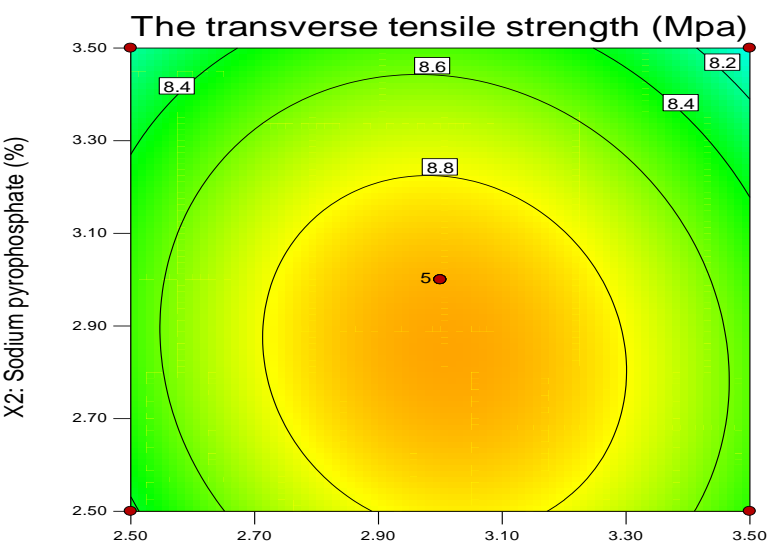

X1: Sodium alginate $(\%)$

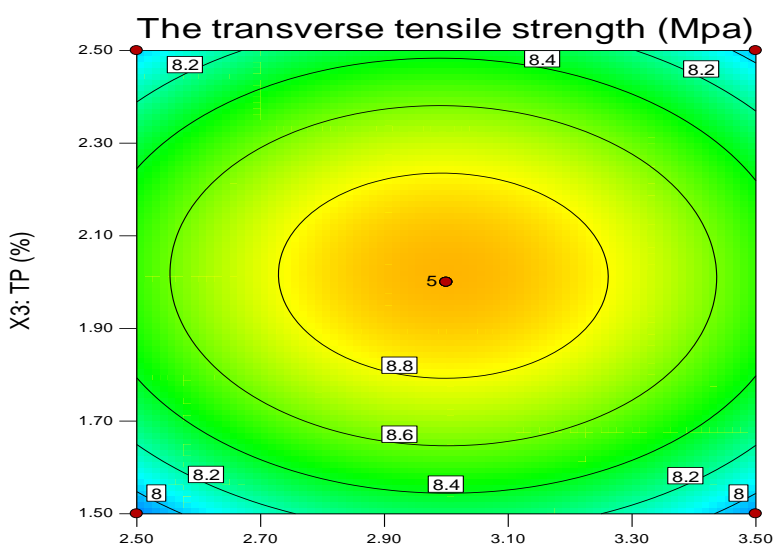

X1: Sodium alginate $(\%)$

\section{The transverse tensile strength (Mpa)}

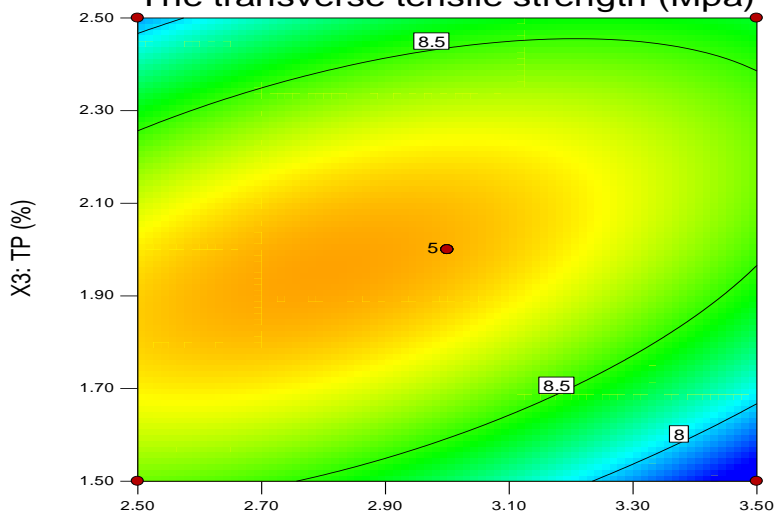

X2: Sodium pyrophosphate (\%)

(C)

Fig. 5: Response surface plots (3D) and contour plots of transverse tensile strength as a function of significant interaction between factors. (A) Concentration of sodium alginate and sodium pyrophosphate; (B) Concentration of sodium alginate and TP; (C) Concentration of sodium pyrophosphate and TP 


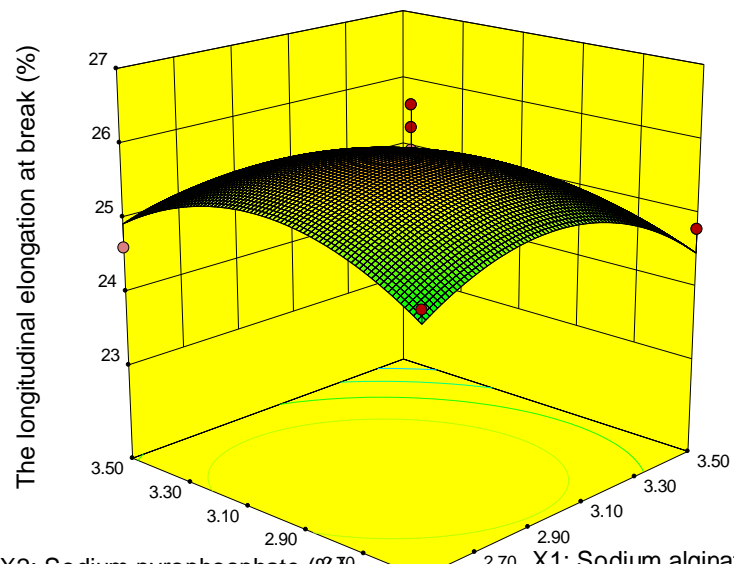

X2: Sodium pyrophosphate $(\%) \quad 2.50 \quad 2.50 \quad 2.70 \quad \times 1$ : Sodium alginate $(\%)$

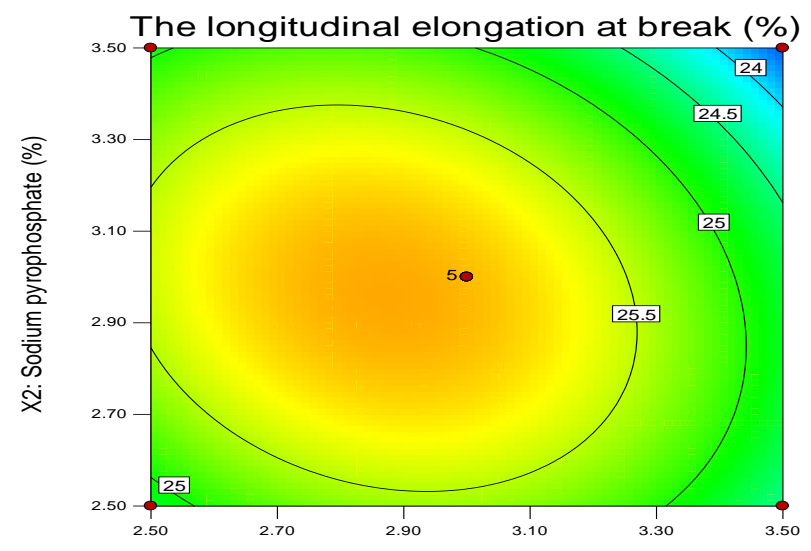

X1: Sodium alginate $(\%)$

(A)
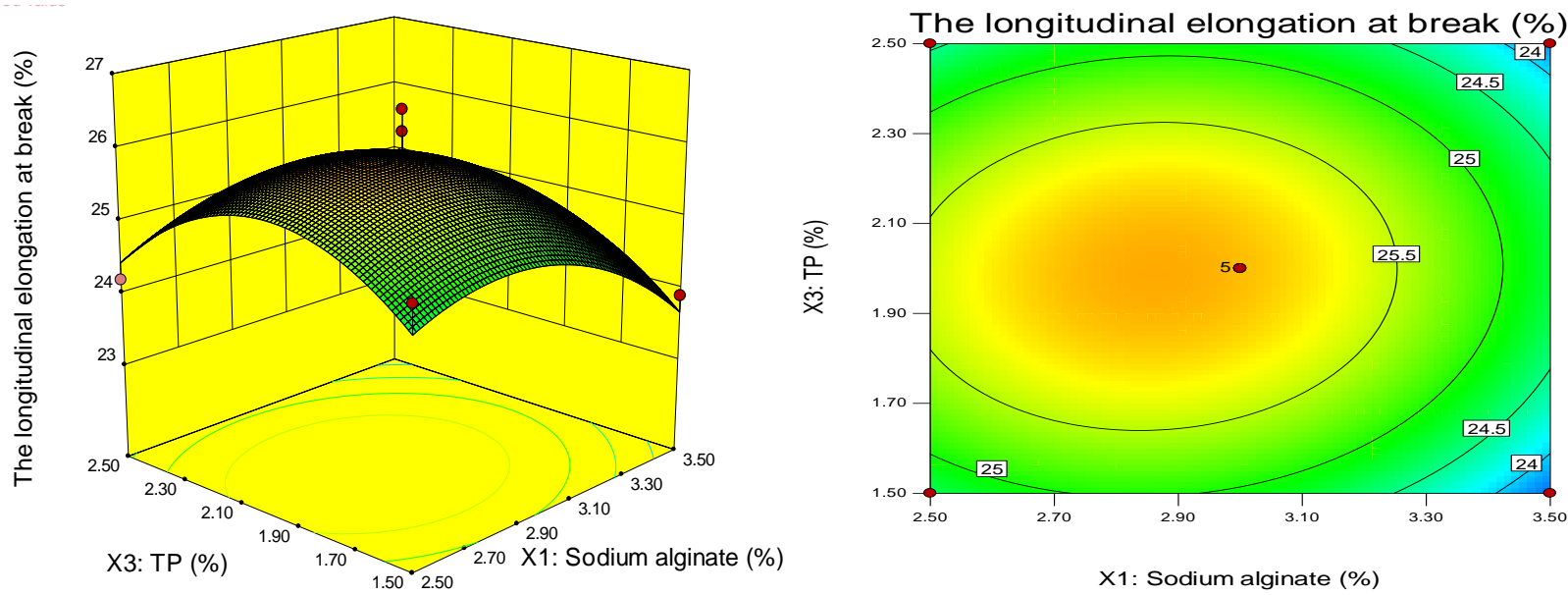

X1: Sodium alginate $(\%)$

(B)
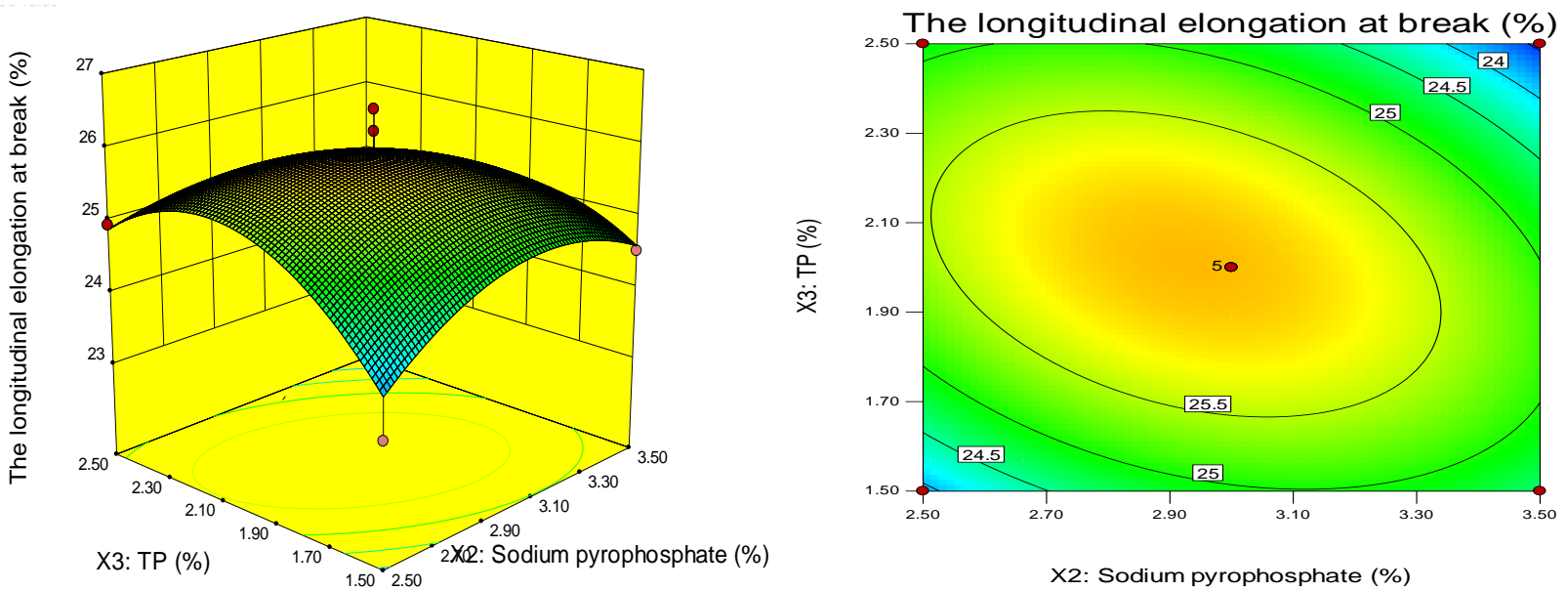

(C)

Fig. 6: Response surface plots (3D) and contour plots of longitudinal elongation at break as a function of significant interaction between factors. (A) Concentration of sodium alginate and sodium pyrophosphate; (B) Concentration of sodium alginate and TP; (C) Concentration of sodium pyrophosphate and TP 


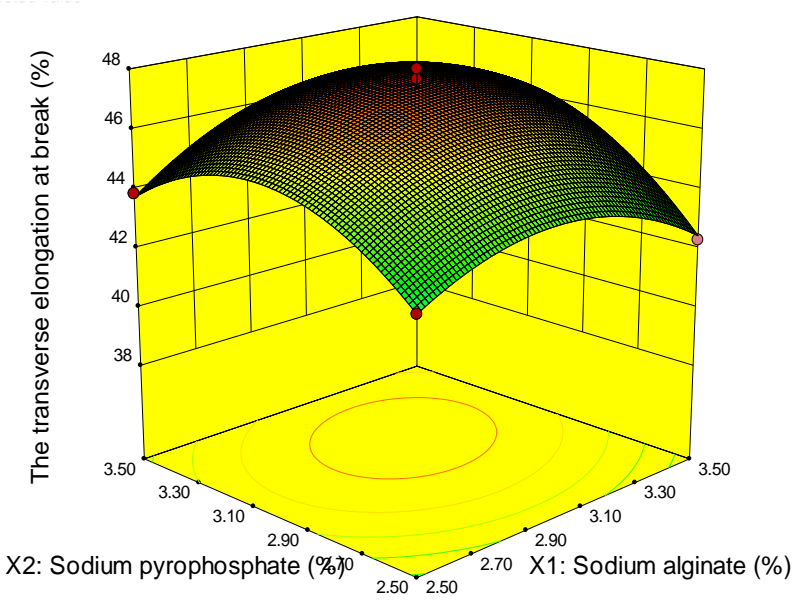

(A)

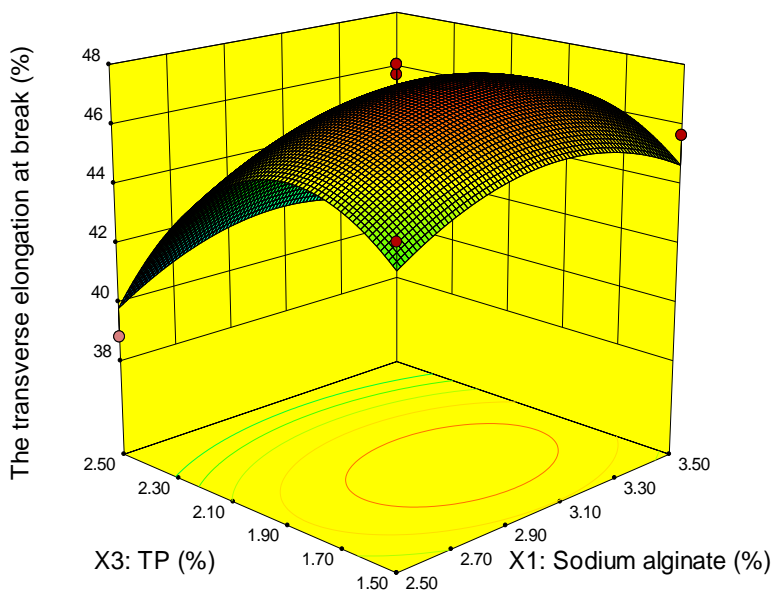

(B)

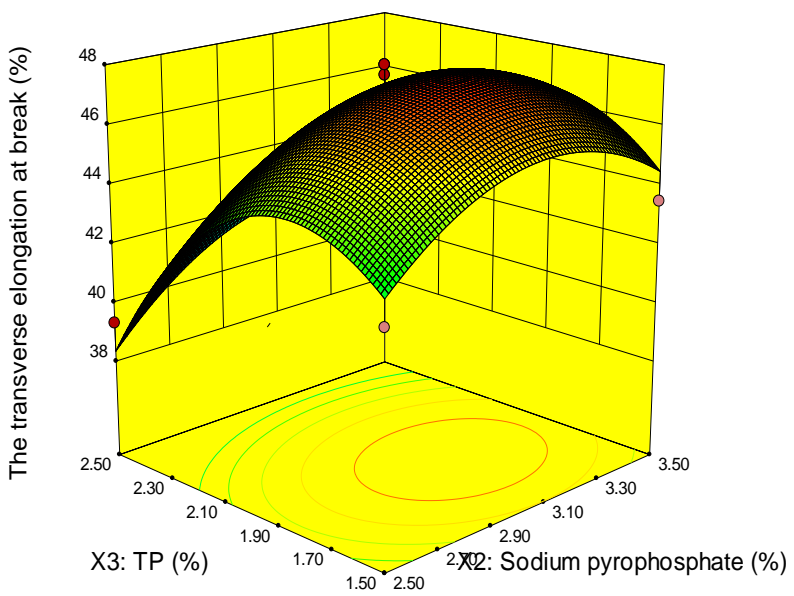

(C)

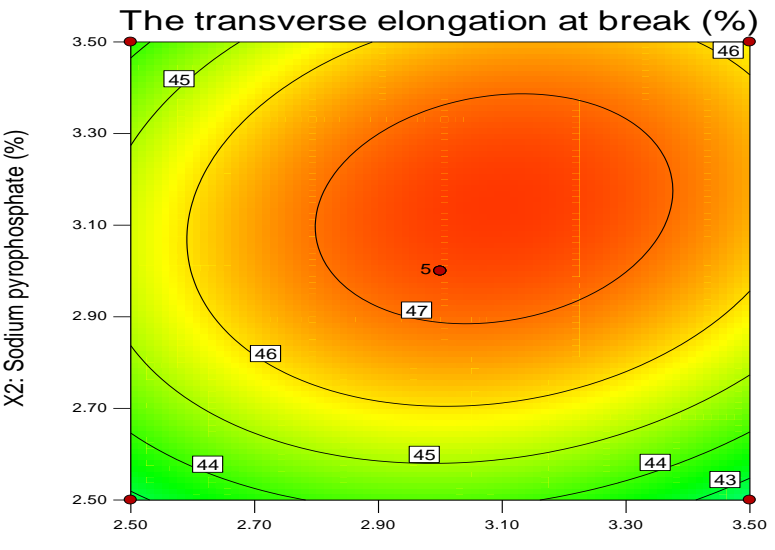

X1: Sodium alginate $(\%)$

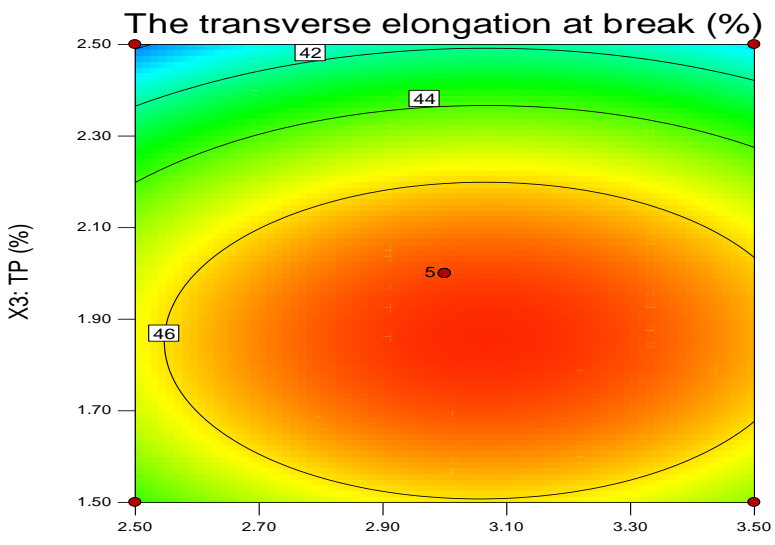

X1: Sodium alginate $(\%)$

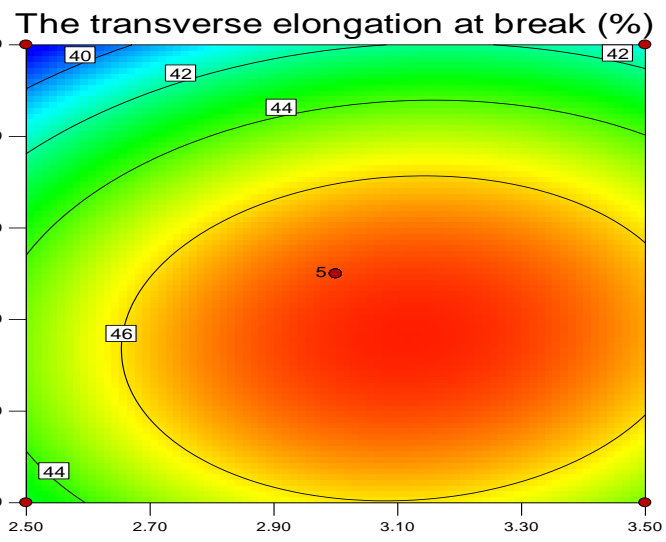

X2: Sodium pyrophosphate (\%)

Fig. 7: Response surface plots (3D) and contour plots of transverse elongation at break as a function of significant interaction between factors. (A) Concentration of sodium alginate and sodium pyrophosphate; (B) Concentration of sodium alginate and TP; (C) Concentration of sodium pyrophosphate and TP 
Table 6: Predicted and experimental response values at optimum conditions

\begin{tabular}{lcc}
\hline Response & Predicted value & Experimental value \\
\hline $\mathrm{Y}_{1}(\mathrm{~N})$ & 12.73390 & $12.65 \pm 0.0608$ \\
$\mathrm{Y}_{2}(\mathrm{~N})$ & 7.54078 & $7.52 \pm 0.1015$ \\
$\mathrm{Y}_{3}(\mathrm{MPa})$ & 10.15980 & $10.21 \pm 0.0916$ \\
$\mathrm{Y}_{4}(\mathrm{MPa})$ & 8.90120 & $8.86 \pm 0.0435$ \\
$\mathrm{Y}_{5}(\%)$ & 25.97350 & $26.05 \pm 0.1000$ \\
$\mathrm{Y}_{6}(\%)$ & 47.22120 & $47.16 \pm 0.0793$ \\
\hline $\mathrm{Y}_{1}(\mathrm{~L})$ &
\end{tabular}

$\mathrm{Y}_{1}=$ Longitudinal tensile force $(\mathrm{N}), \mathrm{Y}_{2}=$ Transverse tensile force $(\mathrm{N}), \mathrm{Y}_{3}=$ Longitudinal tensile strength $(\mathrm{MPa}), \mathrm{Y}_{4}=$ Transverse tensile strength $(\mathrm{MPa}), \mathrm{Y}_{5}=$ Longitudinal elongation at break $(\%), \mathrm{Y}_{6}=$ Transverse elongation at break $(\%)$

The optimum level of different parameters by applying the methodology of desired function was obtained under condition of sodium alginate of $2.90 \%$, sodium pyrophosphate of $2.99 \%$ and TP of $1.99 \%$ with an overall desirability of 0.87 . As shown in Table 6 , the collagen casings were prepared experimentally using the optimized compositions in triplicate and the mechanical properties of these samples were determined to be $12.65 \pm 0.0608 \mathrm{~N}$ of longitudinal tensile force, $7.52 \pm 0.1015 \mathrm{~N}$ of transverse tensile force, $10.21 \pm 0.0916$ $\mathrm{MPa}$ of longitudinal tensile strength, $8.86 \pm 0.0435 \mathrm{MPa}$ of transverse tensile strength, $26.05 \pm 0.0435 \%$ of longitudinal elongation at break and $47.16 \pm 0.0793 \%$ of transverse elongation at break, respectively and no significant differences were found between the predicted values and the experimental values of six responses, demonstrating the validity of the optimized model.

\section{Conclusion}

RSM-BBD was successfully employed to optimize the tensile force, tensile strength and elongation at break of collagen casing sprayed with different concentration TP, sodium alginate and sodium pyrophosphate. Results demonstrated that TP has a significant influence on tensile force and longitudinal tensile strength, sodium alginate and sodium pyrophosphate have a significant effect on transverse elongation at break. Based on the model, the optimum condition of the collagen casing was selected with addition of $2.90 \%$ sodium alginate, $2.99 \%$ sodium pyrophosphate and $1.99 \%$ TP. The optimum set of the independent variables was predicted numerically to obtain the desired levels of longitudinal tensile force $(12.7339 \mathrm{~N})$, transverse tensile force $(7.54078 \mathrm{~N})$, longitudinal tensile strength $(10.1598 \mathrm{MPa})$, transverse tensile strength (8.9012 $\mathrm{MPa})$, longitudinal elongation at break $(25.9735 \%)$, transverse elongation at break $(47.2212 \%)$. The corresponding validation responses were longitudinal tensile force $(12.65 \pm 0.0608 \mathrm{~N})$, transverse tensile force $(7.52 \pm 0.1015 \mathrm{~N})$, longitudinal tensile strength $(10.21 \pm 0.0916 \mathrm{MPa})$, transverse tensile strength $(8.86 \pm 0.0435 \mathrm{MPa})$, longitudinal elongation at break $(26.05 \pm 0.1000 \%)$, transverse elongation at break
$(47.16 \pm 0.0793 \%)$. In a similar type of study, the optimal film formulation has been investigated by using RSM such as the effects of chitosan, glycerin and drying temperature on the response variables of chitosan food film and the effects of wheat gluten, carboxymethyl cellulose and cellulose nanofiber on the water vapor permeability of new biodegradable nanocomposite films (Singh et al., 2015; Bagheri et al., 2019). Thus, the development of collagen casing formulation prayed with TP, sodium alginate and sodium pyrophosphate has been successfully optimized and can be exploited to be used as packaging in sausage industry.

\section{Acknowledgement}

This work was supported by Shandong Provincial Natural Science Foundation, China (No. ZR2014CQ002 and No. ZR2019BC104) and SDUT and Zibo City Integration Development Project (2017ZBXC004). Therefore, we are grateful for the funding and support of this research.

\section{Funding Information}

This work was supported by Shandong Provincial Natural Science Foundation, China (No. ZR2014CQ002 and No. ZR2019BC104) and SDUT and Zibo City Integration Development Project (2017ZBXC004).

\section{Author's Contributions}

Zhike Xie: Participated in the whole experiment process and also contributed to the interpretation of the results and manuscript preparation.

Ming He and Yuhan Zhai: Participated in part of the experimental design.

Feifei Xin and Shuyan Yu: Data curation.

Shaoxuan Yu: Ameliorated the manuscript.

Huanying Zhao: Contributed to the preparation of collagen casings.

Haifang Xiao: Contributed to the study design, the interpretation of the results and manuscript preparation.

Yuanda Song: Contributed to the guidance of experimental design and ameliorated the manuscript. 


\section{Ethics}

This article is original and contains unpublished material. The corresponding author confirms that all of the other authors have read and approved the manuscript and no ethical issues involved.

\section{References}

Aziz, M. S. A., Salama, H. E., \& Sabaa, M. W. (2018). Biobased alginate/castor oil edible films for active food packaging. LWT, 96, 455-460.

Adzaly, N. Z., Jackson, A., Kang, I., \& Almenar, E. (2016). Performance of a novel casing made of chitosan under traditional sausage manufacturing conditions. Meat science, 113, 116-123.

Azam, S., Hadi, N., Khan, N. U., \& Hadi, S. M. (2004). Prooxidant property of green tea polyphenols epicatechin and epigallocatechin-3-gallate: implications for anticancer properties. Toxicology in vitro, 18(5), 555-561.

Bagheri, V., Ghanbarzadeh, B., Ayaseh, A., Ostadrahimi, A., Ehsani, A., Alizadeh-Sani, M., \& Adun, P. A. (2019). The optimization of physicomechanical properties of bionanocomposite films based on gluten/carboxymethyl cellulose/cellulose nanofiber using response surface methodology. Polymer Testing, 78, 105989.

Chen, X., Zhou, L., Xu, H., Yamamoto, M., Shinoda, M., Tada, I., ... \& Yamane, H. (2019). The structure and properties of natural sheep casing and artificial films prepared from natural collagen with various crosslinking treatments. International journal of biological macromolecules, 135, 959-968.

Dou, L., Li, B., Zhang, K., Chu, X., \& Hou, H. (2018). Physical properties and antioxidant activity of gelatin-sodium alginate edible films with tea polyphenols. International journal of biological macromolecules, 118, 1377-1383.

Frei, B., \& Higdon, J. V. (2003). Antioxidant activity of tea polyphenols in vivo: evidence from animal studies. The Journal of nutrition, 133(10), 3275S-3284S.

Gao, C., Pollet, E., \& Avérous, L. (2017). Properties of glycerol-plasticized alginate films obtained by thermo-mechanical mixing. Food Hydrocolloids, 63, 414-420.

Gómez-Estaca, J., Montero, P., Fernández-Martín, F., \& Gómez-Guillén, M. C. (2009). Physico-chemical and film-forming properties of bovine-hide and tuna-skin gelatin: A comparative study. Journal of Food Engineering, 90(4), 480-486.

Harper, B. A., Barbut, S., Lim, L. T., \& Marcone, M. F. (2012). Microstructural and textural investigation of various manufactured collagen sausage casings. Food research international, 49(1), 494-500.
Hayta, M., \& İşçimen, E. M. (2017). Optimization of ultrasound-assisted antioxidant compounds extraction from germinated chickpea using response surface methodology. LWT, 77, 208-216.

Higdon, J. V., \& Frei, B. (2003). Tea catechins and polyphenols: health effects, metabolism and antioxidant functions.

Jongberg, S., Terkelsen, L. D. S., Miklos, R., \& Lund, M. N. (2015). Green tea extract impairs meat emulsion properties by disturbing protein disulfide cross-linking. Meat science, 100, 2-9.

Kalaycıŏlu, Z., Torlak, E., Akın-Evingür, G., Özen, İ., \& Erim, F. B. (2017). Antimicrobial and physical properties of chitosan films incorporated with turmeric extract. International journal of biological macromolecules, 101, 882-888.

Kim, S., Baek, S. K., \& Song, K. B. (2018). Physical and antioxidant properties of alginate films prepared from Sargassum fulvellum with black chokeberry extract. Food Packaging and Shelf Life, 18, 157-163.

Mahcene, Z., Khelil, A., Hasni, S., Akman, P. K., Bozkurt, F., Birech, K., ... \& Tornuk, F. (2020). Development and characterization of sodium alginate based active edible films incorporated with essential oils of some medicinal plants. International Journal of Biological Macromolecules, 145, 124-132.

Shen, Q. W., \& Swartz, D. R. (2010). Influence of salt and pyrophosphate on bovine fast and slow myosin S1 dissociation from actin. Meat science, 84(3), 364-370.

Singh, T. P., Chatli, M. K., \& Sahoo, J. (2015). Development of chitosan based edible films: process optimization using response surface methodology. Journal of Food Science and Technology, 52(5), 2530-2543.

Thakur, R., Saberi, B., Pristijono, P., Stathopoulos, C. E., Golding, J. B., Scarlett, C. J., ... \& Vuong, Q. V. (2017). Use of response surface methodology (RSM) to optimize pea starch-chitosan novel edible film formulation. Journal of food science and technology, 54(8), 2270-2278.

Vergne, D. M. C., Vasconcelos, A. C. P., Batista, R. A., Freitas, M. M., Júnior, R. L. C. A., de Freitas, O., ... \& Cardoso, J. C. (2018). Collagen modification by Maillard reaction. Journal of Thermal Analysis and Calorimetry, 131(1), 671-679.

Wang, L., Dong, Y., Men, H., Tong, J., \& Zhou, J. (2013). Preparation and characterization of active films based on chitosan incorporated tea polyphenols. Food hydrocolloids, 32(1), 35-41.

Wang, W., Zhang, Y., Ye, R., \& Ni, Y. (2015). Physical crosslinkings of edible collagen casing. International journal of biological macromolecules, 81, 920-925. 
Wu, H., Lei, Y., Zhu, R., Zhao, M., Lu, J., Xiao, D., ... \& $\mathrm{Li}$, S. (2019). Preparation and characterization of bioactive edible packaging films based on pomelo peel flours incorporating tea polyphenol. Food Hydrocolloids, 90, 41-49.

Xie, Z., Yu, S., He, M., Yu, S., Zhao, H., Xiao, H., \& Song, Y. (2020). Preparation of Antimicrobial Collagen Casings with High Mechanical Properties. American Journal of Biochemistry and Biotechnology, 16(3), 407-416.
Zhang, W., \& Jiang, W. (2020). Antioxidant and antibacterial chitosan film with tea polyphenolsmediated green synthesis silver nanoparticle via a novel one-pot method. International journal of biological macromolecules, 155, 1252-1261. 